\title{
Fractionation and extraction of bio-oil for production of greener fuel and value-added chemicals: Recent advances and future prospects
}

\author{
Yi Herng Chan ${ }^{\mathrm{a}, *}$, Soh Kheang Loh ${ }^{\mathrm{b}, *}$, Bridgid Lai Fui Chin ${ }^{\mathrm{c}}$, Chung Loong Yiin ${ }^{\mathrm{d}}$, Bing Shen How ${ }^{\mathrm{e}}$, \\ Kin Wai Cheah ${ }^{\mathrm{f}, g}$, Mee Kee Wong ${ }^{\mathrm{a}}$, Adrian Chun Minh Loy ${ }^{\mathrm{h}}$, Yong Ling Gwee ${ }^{\mathrm{f}, \mathrm{g}}$, \\ Shirleen Lee Yuen Lo ${ }^{\mathrm{e}}$, Suzana Yusup ${ }^{\mathrm{f}, \mathrm{g}}$, Su Shiung Lam ${ }^{\mathrm{i}, \mathrm{j}, *}$ \\ ${ }^{a}$ PETRONAS Research Sdn. Bhd. (PRSB), Lot 3288 \& 3289, Off Jalan Ayer Itam, Kawasan Institusi Bangi, 43000 Kajang, Selangor, Malaysia \\ ${ }^{\mathrm{b}}$ Energy and Environmental Unit, Engineering and Processing Division, Malaysian Palm Oil Board, 6 Persiaran Institusi, Bandar Baru Bangi, 43000 Kajang, Selangor, Malaysia \\ ${ }^{\mathrm{c}}$ Department of Chemical Engineering, Faculty of Engineering and Science, Curtin University Malaysia, CDT 250, 98009 Miri, Sarawak, Malaysia \\ ${ }^{\mathrm{d}}$ Department of Chemical Engineering and Energy Sustainability, Faculty of Engineering, Universiti Malaysia Sarawak (UNIMAS), 94300 Kota Samarahan, Sarawak, \\ Malaysia \\ ${ }^{\mathrm{e}}$ Research Centre for Sustainable Technologies, Faculty of Engineering, Computing and Science, Swinburne University of Technology, Jalan Simpang Tiga, 93350 Kuching, \\ Sarawak, Malaysia \\ ${ }^{\mathrm{f}}$ Biomass Processing Laboratory, HICoE - Centre for Biofuel and Biochemical Research, Institute of Self-Sustainable Building, Universiti Teknologi PETRONAS, 32610 Seri \\ Iskandar, Perak, Malaysia \\ ${ }^{\mathrm{g}}$ Chemical Engineering Department, Universiti Teknologi PETRONAS, 32610 Seri Iskandar, Perak, Malaysia \\ ${ }^{\mathrm{h}}$ Department of Chemical Engineering, Monash University, Clayton, Victoria 3800, Australia \\ ${ }^{\mathrm{i}}$ Pyrolysis Technology Research Group, Institute of Tropical Aquaculture and Fisheries (Akuatrop), Universiti Malaysia Terengganu, 21030 Kuala Terengganu, Terengganu, \\ Malaysia
}

${ }^{\mathrm{j}}$ Henan Province Engineering Research Center for Biomass Value-added Products, School of Forestry, Henan Agricultural University, Zhengzhou, 450002, China

\section{H I G H L I G H T S}

- 9 current separation techniques of biooil fractionation/extraction are reviewed.

- Extraction efficiency of bio-oil and their potential applications are reviewed.

- Advantages and challenges of each separation technique are identified.

- Bio-oil refining using organic solvent appears to be most promising for upscaling.

- Oil palm-based bio-oil value chain with conversion technology is promising.
G R A P H I C A L A B S T R A C T

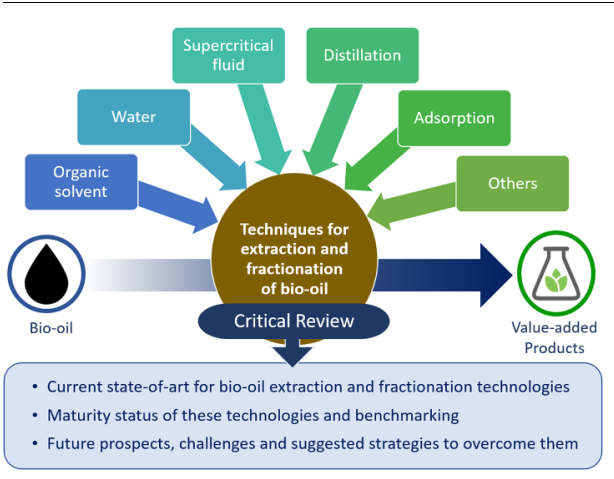

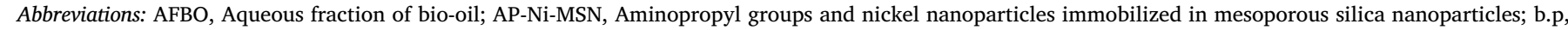

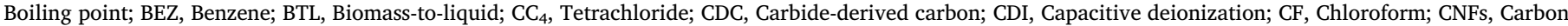

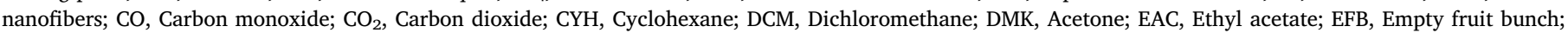

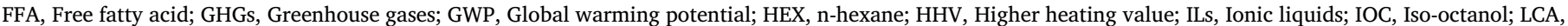

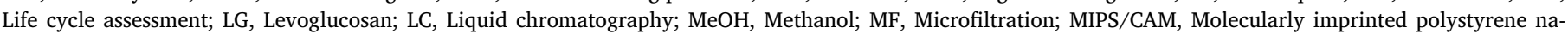

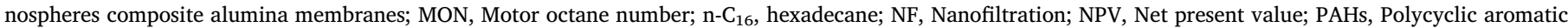

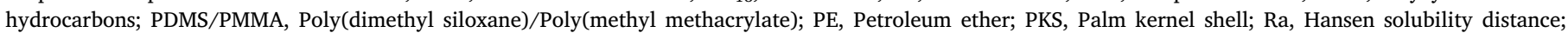

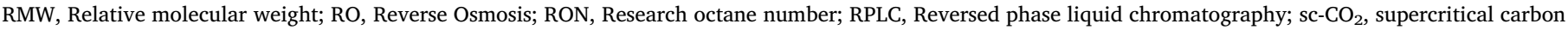

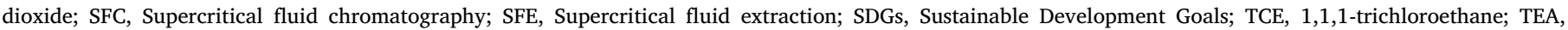
Techno-economic analysis; THF, Tetrahydrofuran; TL, Toluene; UF, Ultrafiltration; VOCs, Volatile organic compounds; W:O, Water-to-oil

* Corresponding authors at: Institute of Tropical Aquaculture and Fisheries, Universiti Malaysia Terengganu, 21030 Kuala Nerus, Terengganu, Malaysia and Henan

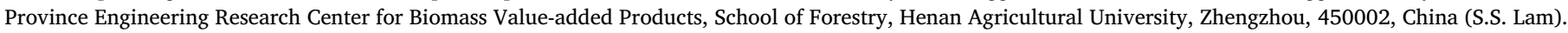

E-mail addresses: chan.yiherng@petronas.com.my (Y.H. Chan), lohsk@mpob.gov.my (S.K. Loh), lam@umt.edu.my (S.S. Lam). 